\title{
Perancangan Sistem Informasi Monitoring Persediaan Bahan Kimia dengan Pendekatan Persediaan Continuous Review (Studi Kasus: Departemen Printing-Dyeing PT Kusumahadi Santosa)
}

\author{
Ikhsan Aditama ${ }^{* 1)}$, Yusuf Priyandari ${ }^{2)}$, Wakhid Ahmad Jauhari ${ }^{3)}$ \\ Jurusan Teknik Industri, Fakultas Teknik, Universitas Sebelas Maret \\ J1. Ir. Sutami 36A Surakarta 57126, Indonesia \\ Email: ikhsan.aditama@gmail.com, priyandari@ft.uns.ac.id,wachid_aj@yahoo.com
}

\begin{abstract}
PT Kusumahadi Santosa is a company engaged in manufacturing, the textile industry. One of the major processes that occurs within the company is printing process where types of chemicals that are used are more than 250 different types. However, in conducting the management of chemical inventories, the company still use the manual process which has not been computerized. As a result, there are some problem occurs, such as miscalculation of 5\%-30\% in the process of recording the amount of chemicals, process of discharging chemicals not recorded, control and planning of chemical inventories is not optimum that will indirectly result in losses company. Therefore, it is necessary to design information system management inventory for controlling chemical inventories. Information system management is designed in the form of web applications and integrated with continuous review inventory model. In addition, the system is equipped with functional and non-functional requirements to fix of the previous system. By adopting the proposed information systems management, the process management of chemicals can be managed more effectively and efficiently. The proposed information system which integrated the system with continuous review inventory model can be adopted by the company for managing the inventories and reducing the inventory cost.
\end{abstract}

Keywords: Continuous Review, Inventory, Management Information System.

\section{PENDAHULUAN}

Manajemen persediaan merupakan salah satu aspek yang sangat penting yang harus diperhatikan dalam suatu perusahaan. Menurut Bahagia (2006), manajemen persediaan menjadi salah satu aspek penentu keberhasilan dalam suatu usaha baik pada perusahaan jasa maupun perusahaan manufaktur. Adanya persediaan dipandang sebagai pemborosan sehingga keberadaannya perlu dihilangkan atau diminimalkan. Namun, kondisi persediaan yang minimal menimbulkan potensi ketidakmampuan untuk memenuhi permintaan sehingga menjadikan kerugian besar bagi suatu perusahaan.

PT Kusumahadi Santosa merupakan sebuah perusahaan yang bergerak dalam bidang manufaktur yaitu industri tekstil. PT Kusumahadi Santosa secara umum memiliki dua proses besar yaitu proses weaving dan proses printing. Proses weaving merupakan proses pengolahan benang menjadi kain yang belum diwarnai. Proses printing merupakan proses pewarnaan atau pemberian motif warna pada kain putih. Sebagai perusahaan yang bergerak dalam industri tekstil, salah satu bahan utama yang digunakan dalam proses printing adalah bahan-bahan kimia. Bahan-bahan kimia dalam proses printing digunakan mulai dari proses persiapan printing hingga proses finishing printing. Jenis dari bahan-bahan kimia yang digunakan mencapai lebih dari 250 jenis sehingga untuk mengelola bahan-bahan kimia tersebut diperlukan suatu pengelolaan yang baik.

Departemen Printing-Dyeing PT Kusumahadi Santosa dalam melakukan pengelolaan persediaan bahan kimia masih menggunakan proses secara manual atau belum terkomputerisasi,

\footnotetext{
*Correspondance : ikhsan.aditama@gmail.com
} 
baik pada proses pengajuan permintaan, penerimaan, pemakaian, maupun pemantauan stok harian bahan kimia. Akibatnya proses-proses yang dilakukan secara manual tersebut menimbulkan beberapa permasalahan.

Permasalahan yang dihadapi PT Kusumahadi Santosa adalah: Pertama, pengelolaan persediaan bahan kimia secara manual mengakibatkan adanya kesalahan hitung antara 5\%-30\% pada proses pencatatan jumlah bahan kimia yang masuk ke gudang maupun keluar dari gudang. Kedua, adanya proses pemakaian bahan kimia yang tidak tercatat. Hal ini dikarenakan adanya beberapa pihak yang membutuhkan bahan kimia langsung mengambil bahan kimia sendiri tanpa melalui petugas gudang. Permasalahan-permasalahan tersebut menyebabkan terjadinya ketidaksesuaian antara jumlah persediaan yang tertulis di dalam buku stok dengan jumlah persediaan yang sebenarnya. Ketiga, pengendalian dan perencanaan persediaan bahan kimia yang belum optimal. Banyak ditemukan jenis bahan kimia yang memiliki jumlah persediaan terlalu banyak maupun terlalu sedikit terutama pada jenis zat warna. Hal ini dikarenakan adanya permintaan kain dengan motif dan warna yang sangat beragam dan sulit diprediksi sehigga menyebabkan kebutuhan bahan kimia terutama pada zat warna yang tidak menentu.

Perbaikan proses pengelolaan, perencanaan, dan pengendalian bahan kimia pada PT. Kusumahadi Santosa perlu dilakukan untuk mengatasi permasalahan-permasalahan yang terjadi. Upaya perbaikan proses pengelolaan, perencanaan, dan pengendalian persediaan bahan kimia dilakukan dengan membuat sistem informasi manajemen persediaan bahan kimia. Menurut penelitian yang telah dilakukan Buwono (2014), perancangan sistem informasi manajemen persediaan dilakukan agar dapat membantu perusahaan dalam proses pencatatan, pengendalian, dan perencanaan persediaan sehingga informasi yang dihasilkan dapat lebih cepat, akurat, dan efisien.

Sistem informasi yang dibangun perlu dilengkapi kebutuhan fungsional dan kebutuhan non fungsional. Kebutuhan fungsional dan non fungsional pada sistem informasi harus dipikirkan dengan cermat agar dapat memenuhi kebutuhan pengguna (Sumariani, 2015). Selanjutnya, sistem informasi manajemen dirancang dengan adanya pengelolaan pengendalian persediaan dengan metode continuous review. Penggunaan metode persediaan tersebut dipilih karena adanya kesamaan karakteristik persediaan dengan penelitian-penelitian terdahulu. Menurut beberapa penelitian terdahulu, penggunaan metode continuous review karena adanya pola permintaan yang bersifat probabilistik (Veravati dkk, 2015) dan perlu adanya pengawasan rutin untuk menjamin ketersediaan barang (Hutomo, 2015; Gozali dkk, 2013). Hubungan antara kebutuhan sistem dengan model persediaan salah satunya pada modul monitoring, dimana merupakan hasil integrasi antara kebutuhan fungsional dengan pengendalian persediaan menggunakan metode continuous review.

Berdasarkan uraian mengenai permasalahan-permasalahan yang dihadapi oleh Departemen Printing-Dyeing PT Kusumahasi Santosa dalam mengelola persediaan bahan kimia, maka tujuan dari penelitian ini adalah merancang sistem infomasi persediaan bahan kimia sebagai upaya memberikan rekomendasi dan kemudahan bagi perusahaan dalam pengelolaan persediaan bahan kimia.

\section{METODOLOGI}

\subsection{Analisis Sistem Awal}

Analisis sistem awal bertujuan untuk mengetahui bagaimana proses yang berlangsung secara keseluruhan pada Departemen Printing-Dyeing PT Kusumahadi Santosa terutama pada bagian gudang bahan kimia.

\subsection{Analisis Sistem Usulan}

Analisis sistem usulan bertujuan untuk menentukan perbaikan apa saja yang harus dilakukan terhadap kekurangan atau kelemahan yang ditimbulkan oleh sistem awal. Analisis sistem usulan ini akan menghasilkan sebuah rancangan sistem yang baru sebagai dasar perancangan sistem informasi manajemen persediaan bahan kimia.

\subsection{Perencanaan Kebijakan Persediaan Bahan Kimia}

Persediaan yang mempunyai beragam jenis persediaan perlu dilakukan pengelompokan berdasarkan tingkat kepentingannya (Walters, 2003). Pengelompokkan persediaan bahan kimia 
dilakukan berdasarkan metode analisis ABC. Setelah diperoleh klasifikasi ABC maka dilakukan penentuan kebijakan persediaan dengan menggunakan dengan menggunakan metode continuous review. Menurut Jauhari (2008) langkah-langkah dalam metode continuous review adalah sebagai berikut:

a. Penentuan nilai service level dan nilai $k$

Service level merupakan tingkat pelayanan perusahaan yang diberikan kepada konsumen. Berdasarkan nilai service level maka dapat ditentukan safety factor atau nilai $k$ pada persamaan (1).

$$
k=F_{S}^{-1}(k)=N O R M S I N V(k)
$$

b. Perhitungan nilai $\Psi k$

Nilai $\Psi k$ digunakan untuk menghitung jumlah ekspektasi backorder. Untuk menghitung nilai $\Psi k$ digunakan persamaan (2)

$$
\Psi k=\left\{f_{s}(k)-k\left[1-F_{s}(k)\right]\right\}
$$

$f_{s}$ berdistribusi normal, $\mathrm{x}$ mean $=0$,

c. Perhitungan nilai lot pemesanan $(q)$

Lot pemesanan merupakan jumlah barang yang dipesan oleh perusahaan untuk mengisi kembali persediaan. Untuk menghitung lot pemesanan digunakan persamaan (3).

$$
q=\sqrt{\frac{2 \mathrm{D}(\mathrm{A}+\pi \sigma \sqrt{\mathrm{L}} \psi(k)}{h_{b}}}
$$

Keterangan:

$q \quad=$ Lot pemesanan (unit)

$D=$ Permintaan (unit)

$A \quad=$ Biaya pemesanan (\$order)

$\pi \quad=$ Biaya backorder (\$/unit)

$\sigma=$ Standar deviasi permintaan (unit)

$L \quad=$ Lead time (periode)

$h_{b} \quad=$ Biaya penyimpanan (\$/unit/periode)

$k=$ Safety factor

d. Perhitungan safety stock (SS)

Safety stock merupakan stock pengaman untuk mengantisipasi adanya ketidakpastian permintaan. Untuk menghitung safety stock digunakan persamaan (4)

$$
S S=k \times \sigma \times \sqrt{L}
$$

Keterangan:

SS $=$ Safety stock (unit)

$k=$ Safety factor

$\sigma=$ Standar deviasi permintaan (unit)

$L=$ Lead time (periode)

e. Perhitungan ekspektasi backorder

Ekspektasi backorder merupakan ekspektasi terjadinya permintaan pelanggan yang tidak terpenuhi akibat ketidakcukupan persediaan barang. Untuk menghitung ekspektasi backorder digunakan persamaan (5).

$$
E S=\sigma \sqrt{L} \Psi(k)
$$

Keterangan:

$k=$ Safety factor

$\sigma=$ Standar deviasi permintaan (unit)

$L=$ Lead time (periode)

f. Perhitungan reorder point (ROP)

$R O P$ merupakan titik dimana perusahaan harus melakukan pemesanan kembali untuk mengisi persediaan. Untuk menghitung $R O P$ digunakan persamaan (6)

$$
R O P=D \times L+S S
$$


Keterangan:

$D=$ Permintaan (unit)

$L=$ Lead time (periode)

SS = Safety stock (unit)

g. Perhitungan total biaya persediaan

Total biaya persediaan merupakan biaya persediaan secara keseluruhan meliputi biaya pemesanan, biaya simpan, dan biaya backorder. Untuk menghitung total biaya persediaan digunakan persamaan (7).

$$
T C_{\text {total }}(q, k)=\left(\frac{D}{q}\right) A+h_{b}\left(\frac{q}{2}\right)+k \sigma \sqrt{L}+\left(\frac{D}{q}\right) \pi \sigma \sqrt{L} \Psi(k)
$$

Keterangan:

$D=$ Permintaan (unit)

$q=$ Lot pemesanan (unit)

$A=$ Biaya pemesanan $(\$ /$ order $)$

$h_{b}=$ Biaya penyimpanan $(\$ /$ unit/periode $)$

$\sigma=$ Standar deviasi permintaan (unit)

$L=$ Lead time (periode)

$k=$ Safety factor

\subsection{Tahapan Perancangan Sistem}

Tahapan yang dilakukan dalam melakukan perancangan sistem, yaitu dimulai dengan identifikasi sistem awal, identifikasi kekurangan sistem awal, identifikasi kebutuhan sistem, perencanaan pengendalian persediaan bahan kimia, perancangan sistem usulan, perancangan database, perancangan user interface, dan pembuatan aplikasi

\section{HASIL DAN PEMBAHASAN}

\subsection{Analisis Sistem Awal}

Sebelum melakukan perancangan sistem usulan perlu diketahui bagaimana sistem awal yang berjalan di perusahaan. Terdapat tiga proses bisnis utama yang dijalankan oleh perusahaan, yaitu proses bisnis pengajuan permintaan bahan kimia, pembelian bahan kimia, dan pemakaian bahan kimia. Pada penelitian yang dilakukan, cukup banyak ditemukan permasalahan pada ketiga proses bisnis tersebut. Permasalahan-permasalahan yang terjadi pada umumnya diakibatkan karena proses yang masih manual, sehingga proses yang berlangsung menjadi kurang efektif dan efisien. Selain itu, kebijakan dalam pengelolaan persediaan bahan kimia dinilai belum optimal dimana cenderung menyebabkan kerugian bagi perusahaan.

\subsection{Analisis Sistem Usulan}

Sistem usulan dirancang sebagai perbaikan dari sistem awal atau sistem yang saat ini sedang digunakan. Hasil dari kekurangan sistem awal tersebut kemudian digunakan sebagai dasar untuk dilakukan rancangan perbaikan yang berupa sistem usulan. Selain untuk menutup kekurangan sistem awal, rancangan sistem usulan juga harus mampu memenuhi kebutuhan sistem informasi manajemen bahan kimia yang dirancang. Hasil analisis sistem usulan dapat dilihat pada Tabel 1.

Tabel 1. Hasil Analisis Sistem Usulan

\begin{tabular}{ccll}
\hline No & Proses Bisnis & \multicolumn{1}{c}{ Kekurangan Sistem Awal } & \multicolumn{1}{c}{ Rancangan Sistem Usulan } \\
\hline & & $\begin{array}{l}\text { Petugas adminstrasi dan PPC harus } \\
\text { mengecek kondisi persedian dari } \\
\text { waktu ke waktu }\end{array}$ & $\begin{array}{l}\text { Penambahan notifikasi pada sistem yang dirancang } \\
\text { sebagai informasi persediaan yang menipis. } \\
\text { Notifikasi akan muncul ketika jumlah stok lebih } \\
\text { kecil dari reorder point }\end{array}$ \\
\cline { 3 - 4 } & & $\begin{array}{l}\text { Penentuan jumlah pemesanan dan } \\
\text { Pengajuan }\end{array}$ & $\begin{array}{l}\text { Hasil perhitungan jumlah pemesanan dari } \\
\text { continuous review akan muncul sebagai }\end{array}$ \\
& Permintaan & optimal, sehingga sering & rekomendasi ketika bahan kimia diajukan untuk \\
& Bahan Kimia & menyebabkan perubahan jumlah & dilakukan pemesanan kembali. Periode pemesanan \\
& & pemesanan sebelum bahan kimia & juga secara otomatis menyesuaikan kondisi \\
& & persediaan bahan kimia
\end{tabular}




\begin{tabular}{|c|c|c|c|}
\hline \multirow[t]{2}{*}{2} & $\begin{array}{l}\text { Pembelian } \\
\text { Bahan Kimia }\end{array}$ & $\begin{array}{l}\text { Pencatatan penerimaan bahan kimia } \\
\text { dari supplier belum dikelompokkan } \\
\text { dengan baik. }\end{array}$ & $\begin{array}{l}\text { Penerimaan bahan kimia di gudang diinput pada } \\
\text { aplikasi dengan dikelompokkan berdasarkan } \\
\text { nomor penerimaan dan supplier pada setiap kali } \\
\text { penerimaan bahan kimia. }\end{array}$ \\
\hline & & $\begin{array}{l}\text { Laporan keseluruhan penerimaan } \\
\text { bahan kimia sulit dikelola dengan } \\
\text { cepat dan akurat }\end{array}$ & $\begin{array}{l}\text { Laporan penerimaan bahan kimia pada aplikasi } \\
\text { dapat ditampilkan dengan cepat berdasarkan semua } \\
\text { data, rentang waktu, maupun berdasarkan supplier }\end{array}$ \\
\hline 3 & $\begin{array}{l}\text { Pemakaian } \\
\text { Bahan Kimia }\end{array}$ & $\begin{array}{l}\text { Pencatatan pemakaian bahan kimia } \\
\text { sering tidak sesuai } \\
\text { Laporan keseluruhan pemakaian } \\
\text { bahan kimia sulit dikelola dengan } \\
\text { cepat dan akurat }\end{array}$ & $\begin{array}{l}\text { Pemakaian bahan kimia di gudang diinput pada } \\
\text { aplikasi dengan dikelompokkan berdasarkan } \\
\text { nomor penerimaan } \\
\text { Laporan pemakaian bahan kimia pada aplikasi } \\
\text { dapat ditampilkan dengan cepat berdasarkan semua } \\
\text { data maupun rentang waktu pemakaian }\end{array}$ \\
\hline
\end{tabular}

\subsection{Perencanaan Kebijakan Persediaan Bahan Kimia}

Sistem informasi manajemen persediaan bahan kimia dirancang dengan adanya integrasi antara aplikasi sistem dengan kebijakan persediaan. Kebijakan persediaan ini digunakan untuk menentukan berapa banyak jumlah bahan kimia yang dipesan, kapan bahan kimia itu dipesan untuk dapat memenuhi persediaan secara optimal. Kebijakan persediaan yang digunakan dalam penelitian ini adalah kebijakan persediaan dengan metode continuous review. Metode ini dipilih karena adanya pola permintaan yang bersifat probabilistik dan adanya pengawasan rutin terhadap bahan kimia untuk menjamin ketersediaan stok untuk proses produksi. Hal ini didukung dengan adanya pencatatan stok bahan kimia setiap hari oleh perusahaan. Berikut ini merupakan hasil kebijakan persediaan yang dapat dilihat pada tabel 2 .

Tabel 2. Kebijakan persediaan dengan metode continuous review

\begin{tabular}{clccccc}
\hline NO & NAMA BAHAN KIMIA & $\begin{array}{c}\text { SERVICE } \\
\text { LEVEL }\end{array}$ & $\begin{array}{c}\text { ORDER } \\
\text { QUANTITY }\end{array}$ & $\begin{array}{c}\text { REORDER } \\
\text { POINT }\end{array}$ & $\begin{array}{c}\text { SAFETY } \\
\text { STOCK }\end{array}$ & $\begin{array}{c}\text { TOTAL } \\
\text { BIAYA (\$) }\end{array}$ \\
\hline 1 & TEXAGAN F-560 & 0,99 & 212 & 373 & 319 & 44,1850 \\
\hline 2 & MINYAK TANAH & 0,97 & 1310 & 1966 & 1033 & 101,9717 \\
\hline 3 & CHLORANYL BLACK PGR & 0,99 & 102 & 105 & 79 & 18,7924 \\
\hline 4 & ETHYL ACETATE & 0,98 & 17 & 32 & 29 & 75,4459 \\
\hline 5 & STORK SCR 100 & 0,98 & 32 & 28 & 22 & 24,7650 \\
\hline$\cdot$ & & $\cdot$ & $\cdot$ & $\cdot$ & $\cdot$ & $\cdot$ \\
\hline$\cdot$ & & $\cdot$ & $\cdot$ & $\cdot$ & $\cdot$ & $\cdot$ \\
\hline 35 & HIDESCO 325 & 0,97 & 144 & 94 & 67 & 9,7015 \\
\hline 36 & REMAZOL BRILL BLUE R SP & 0,96 & 38 & 20 & 16 & 10,8350 \\
\hline 37 & SCREEN NOVA 1750/640/165E & 0,97 & 10 & 6 & 5 & 10,6320 \\
\hline
\end{tabular}

\subsection{Hasil Perancangan Sistem Usulan}

Setelah diperoleh gambaran mengenai sistem usulan, tahapan yang dilakukan adalah perancangan sistem. Perancangan ini berupa pembuatan aplikasi yang berisi logika pemrograman. Perancangan ini dimulai dengan merancang suatu database untuk media penyimpanan informasi sistem. Berikut ini merupakan perancangan database yang disajikan dalam Entity Relationship Diagram (ERD) yang dapat dilihat pada gambar 1.

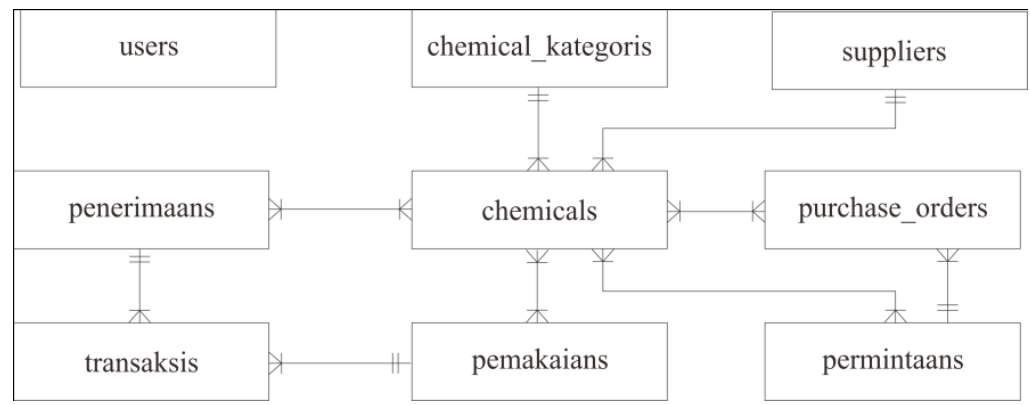

Gambar 1. ERD sistem informasi manajemen persediaan 
Selanjutnya, perlu dilakukan juga rancangan interface untuk mengatur tampilan dari sistem informasi manajemen yang dibuat. Interface bertujuan untuk mempermudah pengguna aplikasi dalam menggunakan fitur-fitur yang ada pada aplikasi. Adapun tampilan yang pertama yang muncul pada saat mengakses aplikasi dapat dilihat pada gambar 2.



Gambar 2. Halaman login

Contoh tampilan lain yaitu form tambah penerimaan bahan kimia dan laporan penerimaan bahan kimia. Form tambah penerimaan berfungsi untuk melakukan pencatatan terhadap bahan kimia yang masuk gudang. Pencatatan ini dikelompokkan berdasarkan supplier. Kemudian, laporan penerimaan berfungsi untuk melihat hasil rekapitulasi semua bahan kimia yang masuk gudang. Laporan penerimaan dapat dilihat berdasarkan semua data, rentang waktu, maupun supplier, sehingga mempermudah pengguna dalam menampilkan data sesuai kebutuhan. Form tambah penerimaan dan laporan penerimaan dapat dilihat pada gambar 3 dan gambar 4 .

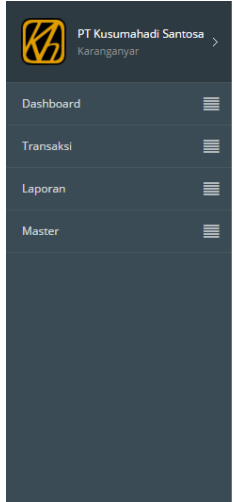

Penerimaan Bahan Kimia

Penentimat

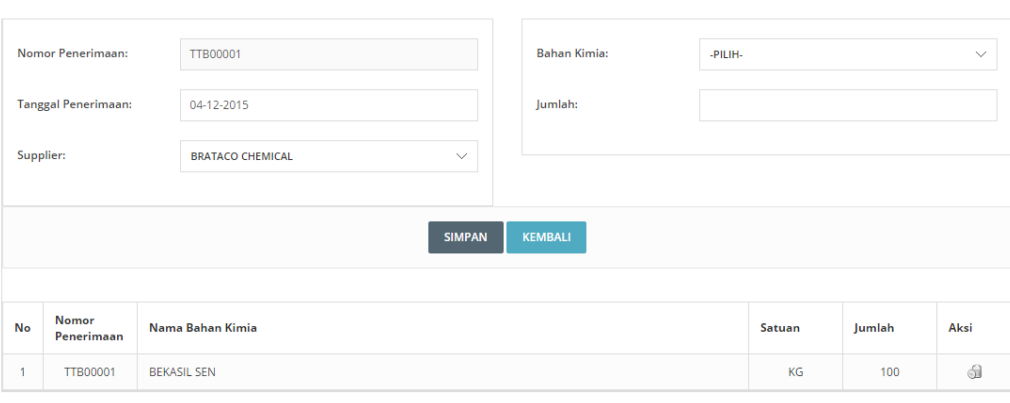

Gambar 3. Form penerimaan bahan kimia
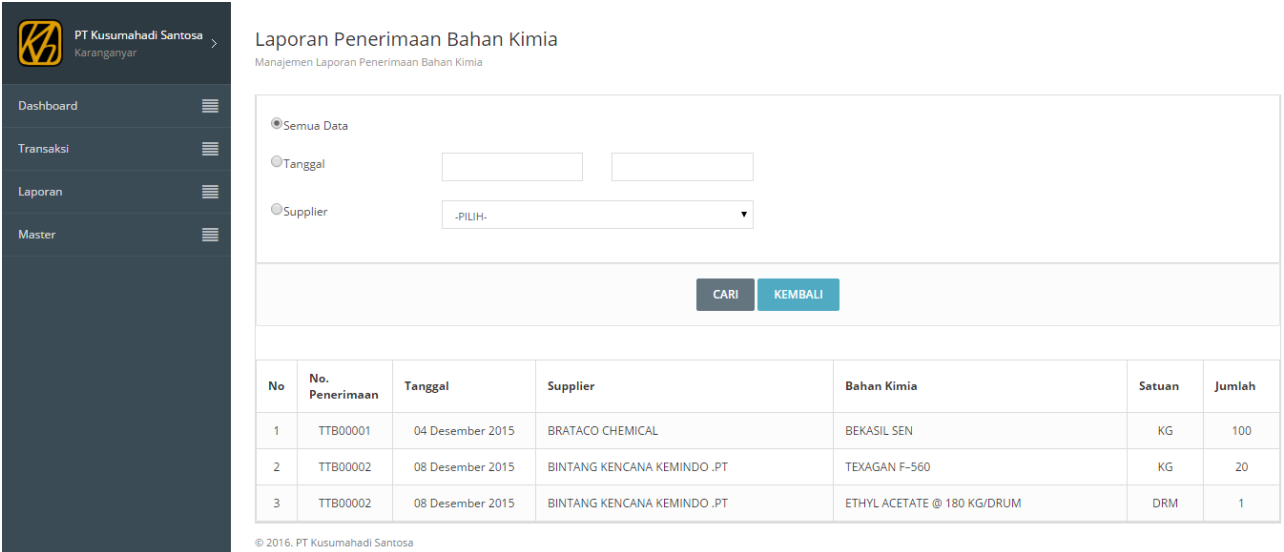

Gambar 4. Laporan penerimaan bahan kimia 
Sistem informasi manajemen persediaan yang dibuat berupa aplikasi ini bertujuan untuk mempermudah perusahaan dalam pengelolaan persediaan bahan kimia. Aplikasi dirancang untuk memenuhi kebutuhan sistem sebagai perbaikan dari kekurangan sistem sebelumnya. Kebutuhan sistem tersebut yaitu, adanya tingkat pengendalian persediaan, pengelolaan proses penerimaan dan pemakaian bahan kimia, pengelolaan pembuatan purchase order, pengelolaan data supplier, pengelolaan laporan penerimaan dan pemakaian bahan kimia, serta adanya notifikasi kondisi persediaan.

Untuk mengakses aplikasi, pengguna perlu melakukan login aplikasi menggunakan akun pengguna. Ada tiga level pengguna utama yang digunakan untuk mengakses aplikasi, yaitu administrasi \& PPC, logistik, dan gudang. Proses yang dilakukan administrasi \& PPC yaitu mengecek apakah terdapat notifikasi persediaan. Notifikasi ini muncul ketika stok bahan kimia berada di bawah nilai rop. Ketika terdapat notifikasi maka administrasi \& PPC harus segera mengajukan permintaan bahan kimia agar segera dipesankan.

Setelah permintaan bahan diajukan, pada bagian logistik akan muncul daftar bahan kimia yang perlu dilakukan pemesanan. Logistik kemudian segera melakukan pemesanan berdasarkan daftar bahan kimia yang diajukan. Status bahan kimia yang diajukan akan berubah menjadi telah dilakukan pemesanan ketika purchase order selesai dibuat. Bahan kimia yang dilakukan pemesanan nantinya akan diterima oleh bagian gudang.

Bahan kimia yang datang kemudian dikelola oleh bagian gudang. Bagian gudang melakukan pencatatan bahan kimia yang datang pada fitur penerimaan bahan kimia. Pencatatan ini dikelompokkan berdasarkan supplier. Setelah bahan kimia masuk, maka kondisi stok akan lebih besar dari nilai rop sehingga notifikasi pada administrasi \& PPC akan hilang secara otomatis. Bagian gudang juga memiliki fungsi dalam pencatatan pengeluaran bahan kimia yang dicatat pada fitur pemakaian bahan kimia.

Selain itu, aplikasi yang dibuat juga dapat digunakan sebagai rekomendasi perusahaan dalam pengambilan keputusan kebijakan persediaan bahan kimia. Hal ini dikarenakan sistem yang dirancang diintegrasikan dengan metode persediaan continuous review, dimana pada metode ini menghasilkan kebijakan persediaan seperti order quantity, safety stock dan reorder point (rop) yang optimal. Untuk menghasilkan kebijakan tersebut perlu dilakukan proses dengan memilih tombol submit pengendalian persediaan pada aplikasi. Secara otomatis aplikasi akan memproses perhitungan kembali nilai order quantity, safety stock, dan rop yang baru. Kemudian nilai paramater tersebut akan tersimpan di dalam database menggantikan data yang lama. Update nilai parameter dalam proses pengendalian persediaan bahan kimia dilakukan setiap tiga bulan sekali. Hal ini dilakukan agar nilai order quantity, safety stock, dan rop menyesuaikan dengan data kebutuhan bahan kimia terbaru.

\subsection{Hasil Implementasi Awal Sistem}

Setelah tahap pembuatan aplikasi selesai, maka perlu dilakukan pengujian aplikasi untuk mengetahui kesiapan dari aplikasi tersebut. Pengujian ini dilakukan dengan melakukan implementasi awal terhadap sistem yang dibuat. Implementasi awal sistem dilakukan di perusahaan dengan uji coba secara langsung oleh pegawai perusahaan. Implementasi awal sistem juga bertujuan untuk mengetahui fungsionalitas sistem secara keseluruhan, serta untuk mengetahui keefektifan dan efisiensi dari sistem.

Pada implementasi awal yang telah dilakukan, masih terdapat beberapa permasalahan fitur aplikasi yang belum berfungsi dengan baik. Walaupun terdapat beberapa permasalahan dalam implementasi awal, secara umum aplikasi dapat berfungsi dengan baik. Permasalahanpermasalahan yang terjadi dapat diselesaikan dengan perbaikan pada pemrogramannya.

Proses pengelolaan bahan kimia pada aplikasi seperti pada proses penerimaan, pemakaian, dan laporan bahan kimia dapat dikatakan berjalan cukup efektif. Hal ini ditunjukkan dengan diperolehnya hasil pengelolaan pada aplikasi yang sesuai dengan keinginan pengguna. Selain itu, dalam pengelolaan bahan kimia juga dapat dikatakan cukup efisien. Hal ini ditujukkan pada saat mengambil data laporan penerimaan maupun pemakaian bahan kimia berlangsung dengan sangat cepat. Berbeda ketika mengambil data laporan dengan proses manual dimana memutuhkan waktu yang cukup lama. 


\section{KESIMPULAN}

Sistem informasi manajemen persediaan bahan kimia dibuat berupa aplikasi pengelolaan persediaan yang berbasis aplikasi website. Aplikasi ini mampu mempermudah dalam pengelolaan persediaan bahan kimia. Hal ini ditunjukkan oleh hasil implementasi awal sistem yang dilakukan, dimana proses-proses pengelolaan penerimaan, pemakaian, dan laporan bahan kimia dapat dikelola lebih efektif dan efisien dengan adanya fitur-fitur pada aplikasi. Selain itu, aplikasi yang dibuat juga sudah dilakukan integrasi antara sistem informasi dengan model persediaan continuous review sebagai upaya penentuan kebijakan persediaan bahan kimia.

Namun, aplikasi ini masih terdapat beberapa penyederhanaan seperti pada fitur dalam penentuan kebijakan persediaan masih terdapat parameter perhitungan bahan kimia yang dibuat statis atau sama untuk setiap jenis bahan kimia. Maka untuk penelitian selanjutnya, aplikasi perlu dikembangkan terutama pada fitur penentuan kebijakan persediaan agar aplikasi dapat berjalan secara dinamis. Selain, itu juga perlu ditambahkan fasilitas export data pada aplikasi dalam bentuk Microsoft Excel maupun dokumen.

\section{DAFTAR PUSTAKA}

Bahagia, S. N. 2006. Sistem Inventori. Penerbit ITB, Bandung.

Buwono, R. I. 2014. Perancangan Sistem Informasi Manajemen Persediaan Obat pada Gudang Farmasi Klinik Umum Rawat Inap Budi Sehat Purworejo. Skripsi. Fakultas Teknik, Universitas Sebelas Maret, Surakarta

Gozali, L., Adianto, Halim, H. 2013. Usulan Sistem Pengendalian Bahan Baku dengan Metode Continuous Review (Q,r) Backorder pada PT. Karuniatama Polypack. Jurnal Ilmiah Teknik Industri Tahun 2013, vol. 1, no. 1, hal 1 - 11

Hutomo, Y. B. 2015. Perancangan Sistem Pendukung Keputusan untuk Manajemen Persediaan Menggunakan Metode Continuous Review di Toko Kalista Fashion. Skripsi. Fakultas Teknik, Universitas Sebelas Maret, Surakarta

Jauhari, W.A. 2008. Penentuan Model Persediaan Spare Part dengan Mempertimbangkan Terjadinya Backorder. Jurnal Gema Teknik, vol 11, hal 6-11.

Sumariani, E. S. 2015. Analisis Kebutuhan Perancangan Sistem Informasi Kesehatan pada Bidang Pelayanan Dinas Kesehatan Kabupaten Boyolali. Skripsi. Program Studi Kesehatan Masyarakat, Universitas Muhammadiyah Surakarta, Surakarta.

Veravati, D. M., Damayanti, D. D. dan Santosa, B. 2015. Perencanaan Kebijakan Persediaan Obat Dengan Menggunakan Metode Probabilistik Continuous Review (s,S) System Pada Bagian Instalasi Farmasi Rumah Sakit AMC. Tel-U Collection. https://repository.telkomuniversity.ac.id/pustaka/100318/ perencanaan-kebijakanpersediaan-obat-dengan-menggunakan-metode-probabilistik-continuous-review-s-ssystem-pada-bagian-instalasi-farmasi-rumah-sakit-amc.html

Waters, D. 2003. Inventory Control and Management. John Wiley \& Sons Ltd. West Sussex 